\title{
PERANCANGAN TAMPILAN VISUAL DOCKING GUIDANCE SYSTEM (VDGS) PADA SISTEM PARKIR PESAWAT TERBANG
}

\author{
Denny Dermawan ${ }^{1)}$, M. Jalu Purnomo ${ }^{2)}$ \\ ${ }^{1}$ T. Elektro Sekolah Tinggi Teknologi Adisutjipto \\ ${ }^{2}$ T. Penerbangan Sekolah Tinggi Teknologi Adisutjipto \\ Jln. Janti Blok R Lanud Adisutjipto, Yogyakarta \\ ${ }^{1}$ dennydermawanstta@gmail.com \\ ${ }^{2}$ Jalu_p@yahoo.com
}

\begin{abstract}
Abstrak
Visual Docking Guidance System (VDGS), adalah alat bantu yang disediakan oleh pihak Bandara untuk membantu seorang Pilot memarkirkan pesawatnya. Kegiatan pengendalian parkir pesawat terbang di Bandara, pilot dibantu oleh seorang Marshaller yang bertujuan untuk menjadi pengarah pergerakan pesawat menuju titik parkir yang benar. Semakin padatnya aktifitas pergerakan pesawat di apron menuntut penggunaan teknologi alternatif sebagai pengganti Marshaller, teknologi ini disebut dengan Visual Docking Guidance Syatem (VDGS, alat bantu parkir pesawat terbang).

Perancangan tampilan VDGS ini menggunakan 3 buah board dot matrix display yang dijadikan menjadi satu sehingga membentuk kombinasi yang sesuai dengan tampilan VDGS yang ada di pasaran. Tampilan yang digunakan adalah led dot matrix superbright. Pengendalinya adalah tiga buah.mikrokontroller PIC 16F84A dan rangkaian register geser untuk menampilkan display gerak ke kanan, ke kiri, lurus dan berhenti serta tampilan identitas pesawat.
\end{abstract}

Kata Kunci : Visual Docking Guidance System (VDGS), mikrokontroller PIC16F84A Led dot matrix.

\section{Abstract}

Visual Docking Guidance System (VDGS), is a device provided by the airport service to assist a pilot parked the plane on the righr place. On Aircraft parking control activities in the airport, the pilot is assisted by a marshaller that aims to be steering the movement of aircraft to the correct parking spot. The more density of the movement of aircraft on the apron activity requires the use of alternative technology to substitute marshaller, this technology is called Visual Docking Guidance Syatem (VDGS).

VDGS display design uses three pieces of board of dot matrix display that is made into one to form a combination in accordance with the appearance on the VDGS on the market. Display used is a superbright LED dot matrix. The controller is a three pieces of PIC 16F84A microcontroller and a series of shift registers to display the movement of the aircraft to the right, to the left, straight and stops and also display the aircraft identity. 
Keywords : Visual Docking Guidance System (VDGS), mikrocontroller PIC16F84A Led dot matrix.

\section{Pendahuluan}

Pertumbuhan transportasi udara dan perkembangan teknologi semakin tahun semakin pesat, hal ini menyebabkan pelayanan bandar udara melampaui kemampuan dalam menyediakan fasilitas untuk memenuhi pertumbuhan secara memadai. Sebagian besar sis tem tranportasi udara di bandar udara ditekan melebihi kemampuan kapasitas rancangan bandar udara yang telah ada, sehingga mengakibatkan memburuknya pelayan di bandar udara.

Dalam transportasi udara, perhatian khusus diberikan pada pergerakan pesawat terbang, penumpang, dan barang, baik melalui bandar udara maupun sistem penerbangan. Demikian gambaran keadaan yang ada di bandara-bandara besar di Indonesia. Karena pertumbuhan transportasi udara semakin tahun semakin pesat.

Di setiap bandar udara banyak kegiatan yang dilakukan, untuk melakukan tugas dan fungsi dari kegiatan yang ada di bandar udara, pihak pengelola bandar udara membentuk beberapa divisi, dinas maupun unit pelayanan untuk mengelola suatu bandar udara. Salah satu unit pelayanan bandar udara tersebut adalah Apron Movement Control (AMC). Divisi ini berada dibawah naungan dinas operasi bandar udara dan di pimpin oleh assisten manager sisi udara. Unit ini mempunyai peran yang sangat penting dalam menyeleng garakan pelayanan yang aman dan nyaman bagi setiap perusahaan yang berger ak dibidang transportasi udara.

Semakin berkembangnya teknologi tidak menuntut kemungkinan pada setiap bandar udara untuk kedepannya setiap pesawat terbang yang akan parkir di parking stand tidak lagi menggunakan marshaller namun menggunakan peralatan yang semakin canggih. Inilah perlunya Rancangan Visual Docking Guidance System Untuk Parking Stand Pesawat terbang.

\section{Dasar Teori}

\subsection{Parking Stand}

Parking stand adalah area dimana pesawat terbang diparkir selama pelayanan darat, dengan jawak minimum 7,5 meter ter hadap sisi pesawat terbang kecuali untuk jarak aman wing tip yang dapat berkurang hingga jarak minimum. Area ini harus aman dari setiap kendaraan atau peralatan selama pesawat terbang bergerak dan diperjelas oleh garis batas peralatan atau aircraft boundary line $(A B L)$.

\subsection{Visual Docking Guidance System}

Visual Docking Guidance System adalah peralatan yang memandu pesawat terbang secara visual menuju ke tempat parkir di Apron secara otomatis. Sistem panduan ini dirancang untuk memberikan penuntun docking dengan cepat halus dan presisi sampai pada gate terminal. Penanda Frekuensi mengontrol jenis pesawat terbang untuk memastikan apakah sesuai dengan informasi yang diberikan untuk docking. Alat ini menampilkan informasi yang jelas dan terlihat oleh pilot pada layar intensitas tinggi LED untuk arah docking yang benar.

Prosedur docking dapat lebih cepat dengan menggunakan docking otomatis dari pada menggunakan marshaller. Parkir tanpa menggunakan marshaller akan lebih efektif karna penggunaan marshaller akan terkendala pada saat cuaca buruk dan memungkinkan staff yang sama untuk mengatasi tugas -tugas lain di apron, serta meminimalkan pergerakan jumlah petugas bandar udara yang bekerja di sekitar apron dengan alasan safety. 


\subsection{Konsep dasar Visual Docking Guidance System}

Konsep dasar dari VDGS adalah sebagai berikut: Sensor yang digunakan di Bandara berupa sensor Laser yang berjenis Laser M1 (Laser yang tidak mengeluarkan cahaya tampak, sehingga aman bagi mata (Pilot)). Sensor ini akan mengirimkan spektrum berkas cahaya yang akan mengenai bodi pesawat, baik main frame pesawat maupun sayap pesawat. Pantulan spektrum ini akan dikembalikan ke arah Laser penerima., setelah itu rangkaian sensor dihubungkan oleh pengirim data. Data yang terbaca oleh sensor akan dikirim dan penerima akan menghubungkan data yang diterima dengan cara menghubungkan ke LED dotmatrix, dotmatrix akan menampilkan karakter sesuai dengan posisi pesawat terbang berada seperti Gambar 1. Panduan yang digunakan adalah panduan untuk sisi Harizontal dan untuk sisi vertikal.

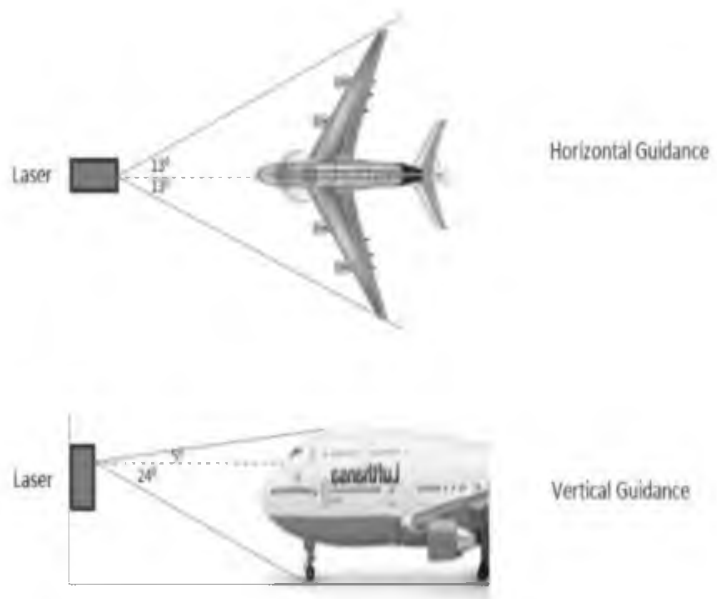

Gambar 1 Konsep dasar VDGS

\subsection{Tampilan}

Tampilan VDGS yang telah terpasang di bandara-bandara Internasional tersaji dalam berbagai bentuk. Beberapa bentuk tampilan yang dipakai pada beberapa Bandara Internasional di belahan dunia adalah seperti diperlihatkan pada gambar 2 sampai dengan gambar 6 .

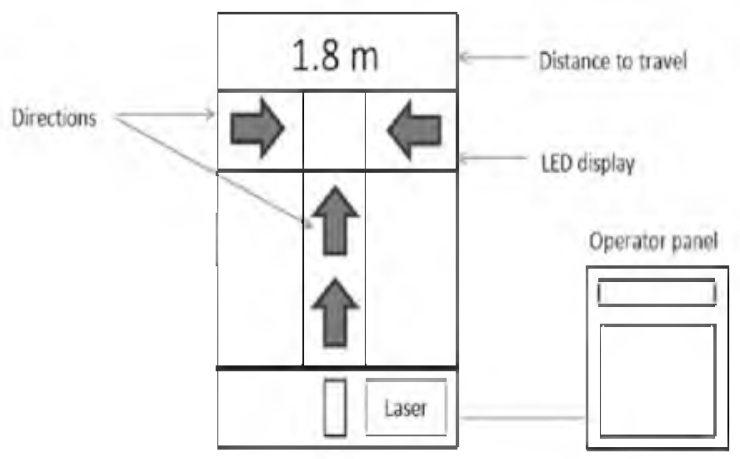

Gambar 2 Konsep Tampilan VDGS

Pada gambar 2, baris pertama adalah informasi jarak pesawat ke Appron. Baris kedua adalah informasi arah pesawat baik ke kiri maupun ke kanan, dan tampilan bagian bawah adalah tampilan untuk bergerak lurus ke arah appron. 


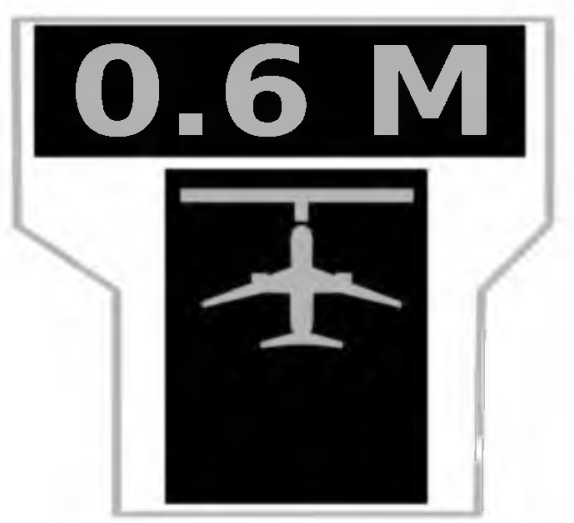

Gambar 3 Tampilan VDGS

Pada gambar 3, baris pertama adalah informasi jarak pesawat ke appron, dan baris kedua adalah nformasi arah gerak pesawat baik ke kiri, ke kanan maupun lurus ke arah appron.

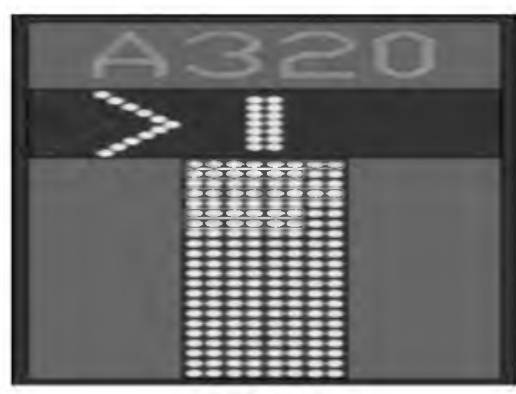

STOP

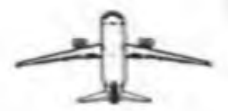

Gambar 4 Indikator pesawat terbang kurang ke kanan

Pada gambar 4, informasi pada baris pertama adalah informasi jenis pesawat yaitu Airbus A 320, baris kedua adalah informasi bahwa pesawat harus berbelok ke kanan dan informasi padaa baris ketiga ketiga adalah informasi jarak pesawat ke appron.

Jika panah menunjukkan arah ke kiri maka pilot harus mengarahkan pesawat terbang ke arah sebelah kiri kiri seperti Gambar 5. Pada gambar juga ditunjukkan bahwa jarak pesawat ke appron sudah cukup dekat.

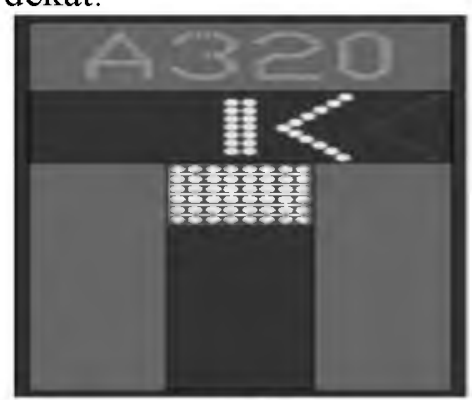

STOP

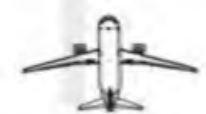

Gambar 5 Indikator pesawat terbang kurang ke kiri 
Bila posisi pesawat terbang sudah mencapai daerah dimana harus berhenti atau posisi sudah tercapai, maka tampilan layar VDGS akan menampilkan STOP seperti Gambar .6.
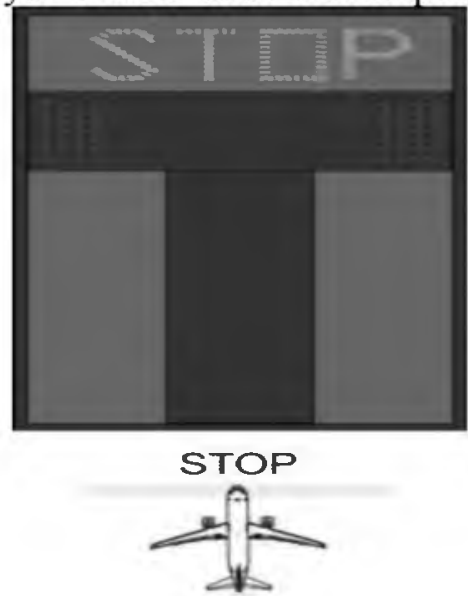

Gambar 6 Tanda berhenti

Kode/jenis pesawat akan ditampilkan saat memasuki area parkir. Tampilan kode pesawat seperti Airbus A320, dan sejenisnya akan ditampilkan ke layar VDGS melalui saklar manual yang akan memilih empat buah jenis/kode pesawat.

\section{Metode Penelitian}

Diagram alir penelitian diperlihatkan pada gambar 7

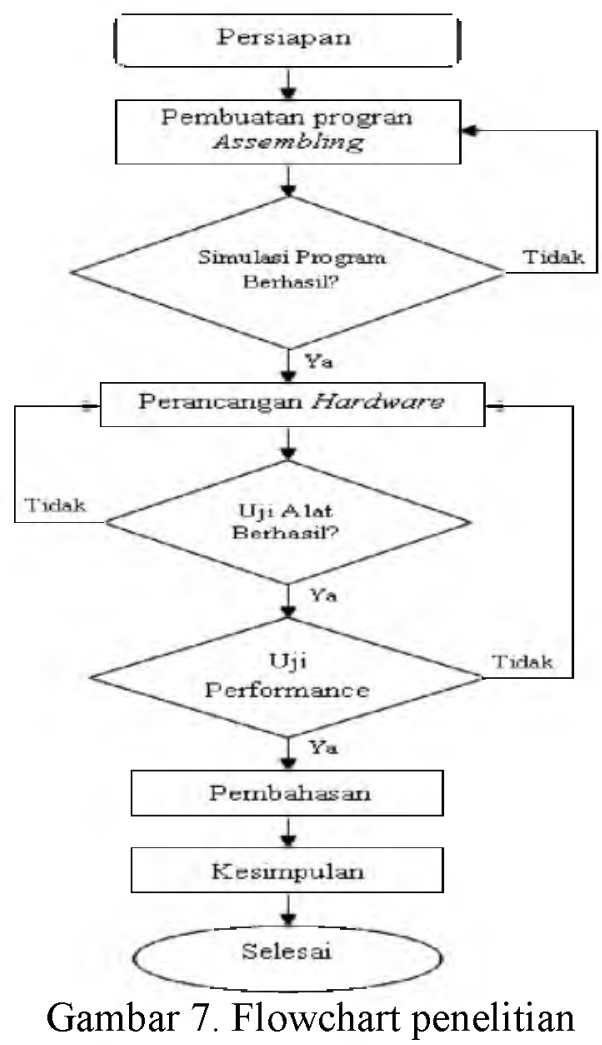

\subsection{Blok diagram perancangan}


Blok diagram perancangan penelitian diperlihatkan pada gambar 8 .

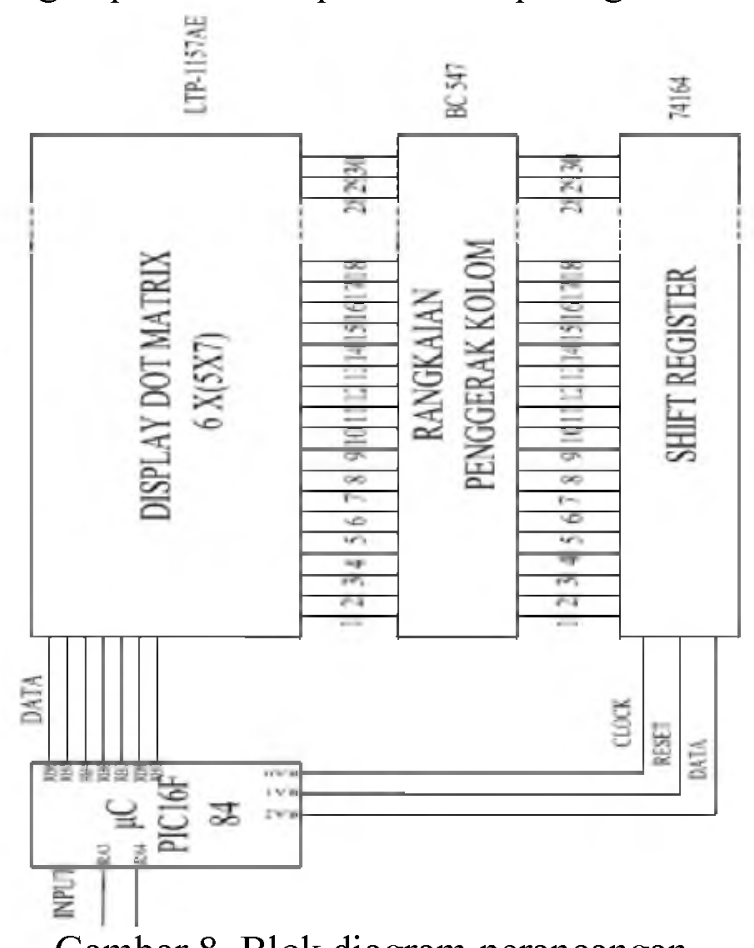

Gambar 8. Blok diagram perancangan

Blok diagram perancangan seperti pada gambar 3.2 terdiri dari : mikrokontroller PIC16F84, display dot matrik, penggerak kolom dan shift register.

LED Dotmatrix display merupakan salah satu yang dapat digunakan untuk menampilkan display dari program yang dibuat yang dikirim secara paralel. Jadi untuk mengkonfigurasikan perlu membuat schematic perancangan terlebih dahulu setelah program yang dibuat jalan barulah memulai merancang sistem yang terhubung dengan LED dotmatrix. Adapun perancangan LED dotmatrix ini adalah seperti gambar 9.

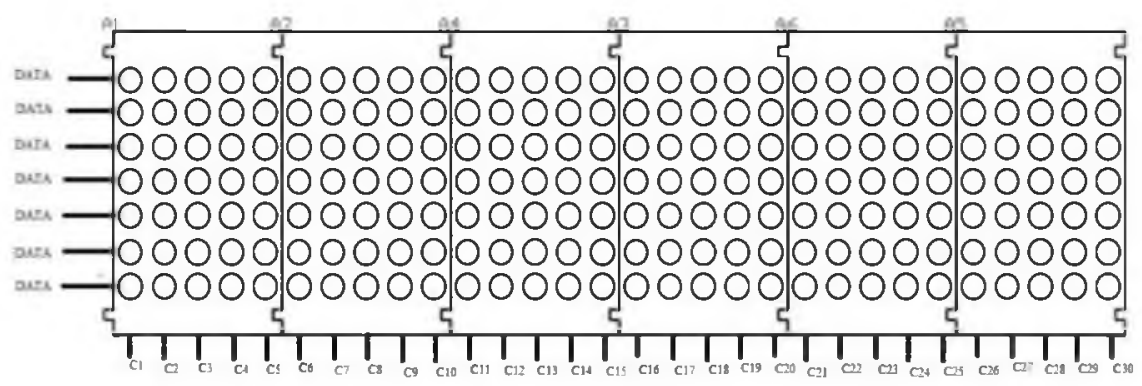

Gambar 9. Rangkaian dot matrik

Rangkaian dot matrik terdiri dari 6 buah dot matrik yang datanya dihubungkan secara paralel. Ada 30 buah kolom yang nantinya akan dihubungkan dengan rangkaian penggerak kolom (transistor BC547) untuk selanjutnya rangkaian penggerak kolom ini akan terhubung dengan rangkaian shift register.

Data diperoleh dari mikrokontroller PIC16F84 yang terhubung secara paralel untuk semua dot matrik, kolom dari dot matrik akan $O N$ atau $O F F$ sesuai dengan data pada shift register, sehingga pengaturan tampilan (mana yang $O N$ dan mana yang $O F F$ ) akan diatur oleh shift register.

Hasil pembuatan dotmatrix menggunakan 18 LED dimana masing-masing LED berisi 5 kolom dan 7 baris untuk 1 led dotmatrix yang diletakkan secara horizontal dan vertikal. 186

Volume VII, Nomor 2, November 2015 
Masing-masing LED punya fungsi tersendiri. Untuk LED yang diletakkan secara horizontal paling atas dibuat untuk tampilan kode pesawat, dan LED secara horizontal di bawahnya dibuat untuk signal indikator tulisan $G O$, kiri, kanan, dan STOP sedangkan LED yang diletakkan secara vertikal khusus untuk signal indikator lurus saja. Tampilan led dot matrik lengkap diperlihatkan pada gambar 10.

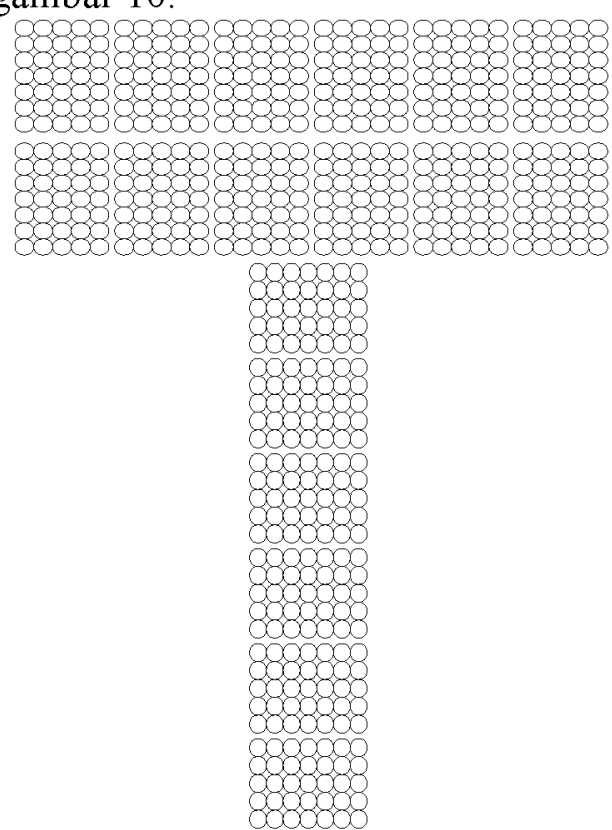

\section{Hasil Pembahasan}

Gambar 10 Tampilan lengkap LED Dotmatrix

Tampilan keluaran pada LED diatur oleh operator menggunakan 2 switch yang terlihat pada tabel 1 dan 2 .

Tabel 1 Output Tampilan VDGS signal indikator

\begin{tabular}{|c|c|c|}
\hline Switch 1 & Switch 2 & Output \\
\hline 0 & 0 & Stop \\
\hline 0 & 1 & Lurus \\
\hline 1 & 0 & Kanan \\
\hline 1 & 1 & Kiri \\
\hline
\end{tabular}

Tabel 2 Output Tampilan VDGS kode pesawat

\begin{tabular}{|c|c|c|}
\hline Switch 3 & Switch 4 & Output \\
\hline 0 & 0 & A-380 \\
\hline 0 & 1 & B-757 \\
\hline
\end{tabular}




\begin{tabular}{|c|c|c|}
\hline 1 & 0 & CN-250 \\
\hline 1 & 1 & ATR-72 \\
\hline
\end{tabular}

Dalam pembuatan alat ini tampilan yang didapatkan sesuai dengan yang diinginkan mulai dari ketepatan sistem pembacaan hingga pengiriman dan penampilan data yang di kirim

Hasil penelitian dari tampilan VDGS yang sudah penulis selesaikan dapat dilihat pada gambar 11 sampai dengan gambar 18 .

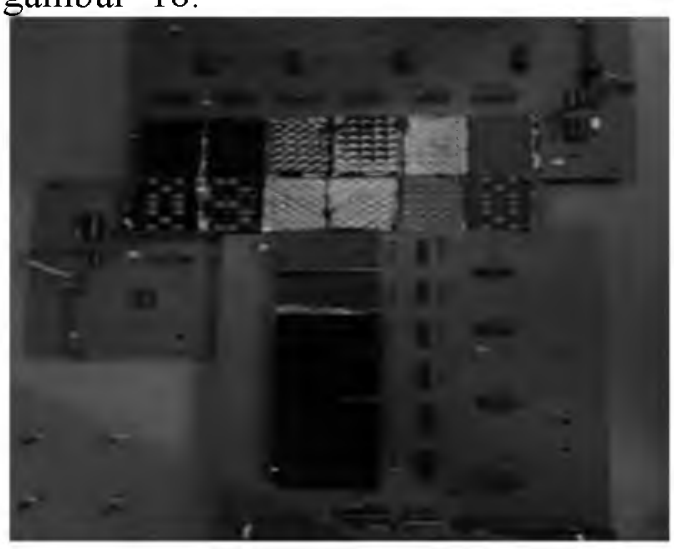

Gambar 11 Indikator STOP

Pada gambar 11, saat switch 1 dan switch 2 berlogika ' 0 ' maka keluaran yang dihasilkan oleh rangkaian dotmatrix yaitu tulisan ' $S T O P$ ',

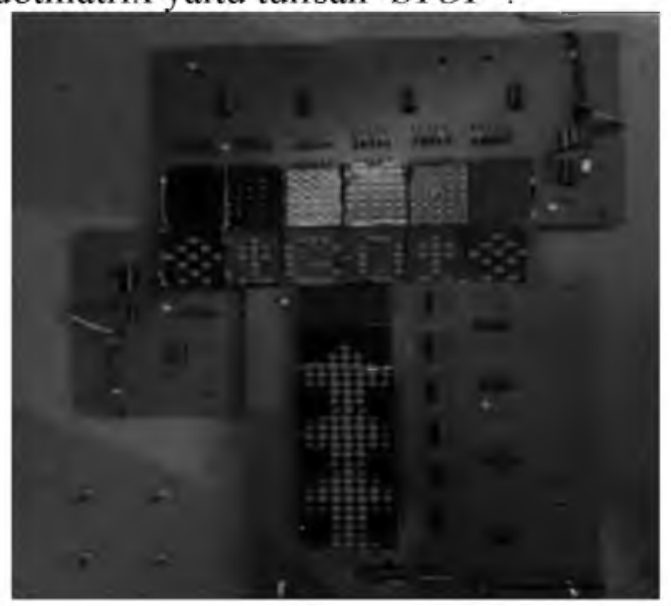

Gambar 12 Indikator lurus

Selanjutnya, pada saat switch 1 berlogika ' 0 ' dan switch 2 berlogika ' 1 ' maka keluaran yang dihasilkan oleh rangkaian dotmatrix yaitu signal indikator lurus atau ' $G O$ ' seperti pada gambar 12 . 


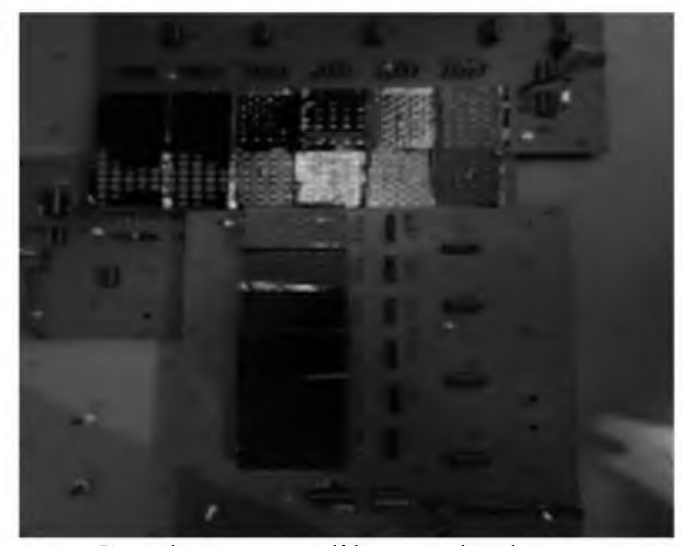

Gambar 13 Indikator ke kanan

Kemudian saat switch 1 berlogika ' 1 ' dan switch 2 berlogika '0' maka keluaran yang dihasilkan oleh rangkaian dotmatrix yaitu signal indikator 'kanan' seperti pada gambar 13.

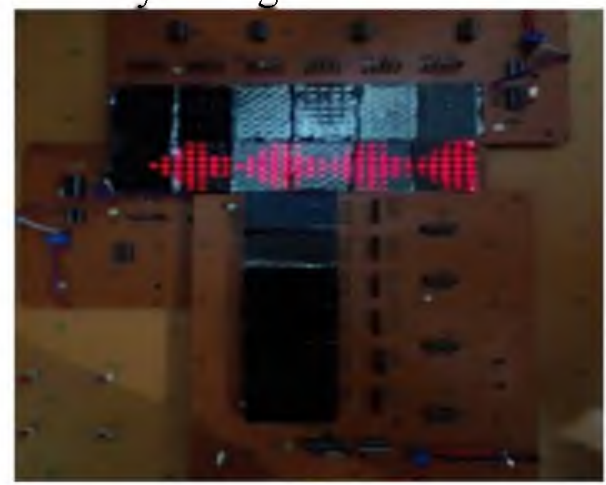

Gambar 14 Indikator signal ke kiri

Pada saat switch 1 dan switch 2 berlogika ' 1 ' maka keluaran yang dihasilkan yaitu indikator signal 'kiri' seperti pada gambar 14.

Sebagai tambahan yaitu adanya kode pesawat yang juga ditampilkan secara manual menggunakan 2 switch. Adapun kode pesawat yang penulis tampilkan adalah A380, B757, ATR72, dan CN250 seperti diperlihatkan pada gambar 15 sampai 18.

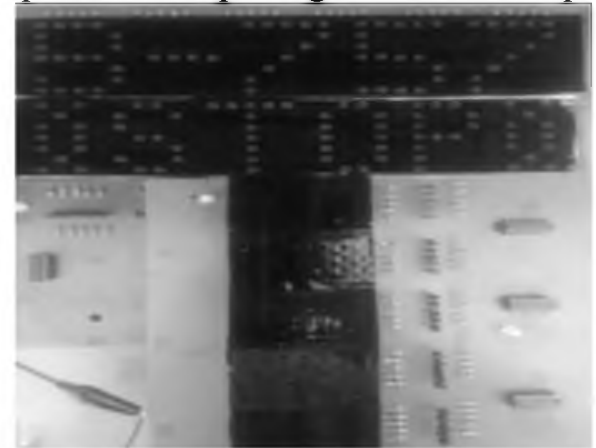

Gambar 15 Kode pesawat B-757 

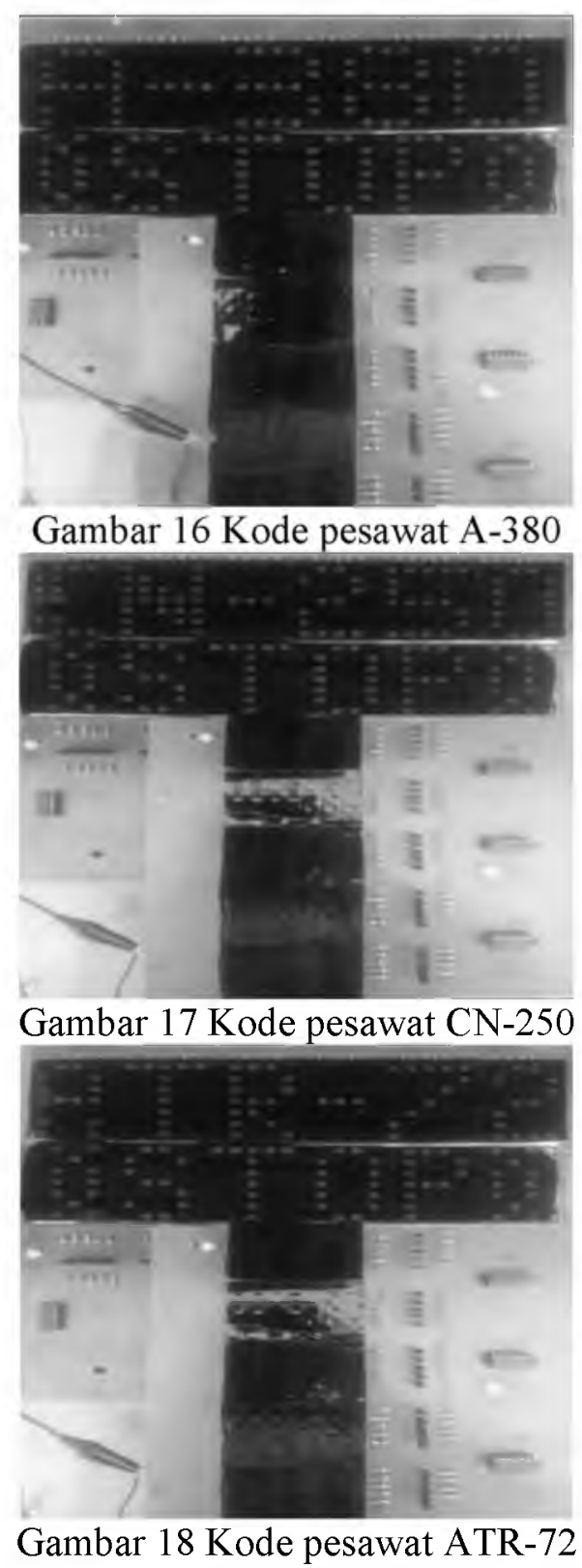

\section{Kesimpulan}

Kesimpulan yang dapat diambil pada penelitian perancangan tampilan Visual Docking Guidance System (VDGS) pada sistem parkir pesawat terbang adalah sebagai berikut :

1. Tampilan Visual Docking Guidance System untuk parking stand pesawat terbang dirangkai melalui proses perancangan sistem LED Dotmatrix.

2. Tampilan VDGS berupa 3 baris led dot matrik yaitu baris pertama akan digunakan sebagai tampilan jenis pesawat, baris kedua berupa informasi gerak ke kiri , ke kanan dan berhenti serta baris ketiga berupa informasi gerak lurus.

3. Pemilihan 4 mode yaitu : mode lurus, mode kurang ke kiri, mode kurang ke kanan dan mode stop dilakukan dengan bentuan saklar mekanis sebagai masukannya.

\section{Daftar Pustaka}


Carlos A D.,2012." Advanced-Visual Docking Guidance System (AVDGS)".

Dermawan D., 2008." Mikrokontroller PIC16F84", STT Adisujipto, Yogyakarta.

Wodzinki T.,2003." Visual Docking Guidance System"

Aviationpros, docking guidance, systems tools for ramp Management, Online, www.aviationpros.com/article/10218389/docking-guidance-, systems-tools-for-rampmanagement. Diakses 6 Juli 2015

Kajianpustaka,2012,mikrokontroler-pic16f84,Online, www.kajianpustaka.com/2012/10/mikrokontroler-pic16f84.html. Diakses 6 Juli 2015

Sloveniacontrol,2012,AIRAC,Online, www.sloveniacontrol.si/acrobat/aip/Operations/201206-28-AIRAC/htm1/eAIP/LJ-AD-2.LJLJ-en-GB.html. Tanggal 6 Juli 2015

Safegate,2014, IDGS ICAO Online, www.safegate.com/tibet/template/media,MediaObjectFile.vm;jsessionid=2C559404E4FFA4 196A703030829ECC7D? siteid=1040\&objectid=6979\&size=large. Diakses 10 Juli 2015 